\title{
The Reinvented Music Teacher-Researcher in the Making: Conducting Educational Development Through Intercultural Collaboration
}

\author{
Vilma Timonen, Anna Houmann, and Eva Sæther
}

\begin{abstract}
Music educators working in cross-cultural contexts are faced with both challenges and possibilities, often finding themselves in need of multidimensional re-invention. This chapter focuses on teacher-researchers, contextualising them within the frame of institutional change and intercultural music teacher education. Taking an active role in educational development and regenerating usual patterns of action in music-education institutions sets various challenges as well as opportunities for the teacher-researchers involved. In this chapter we reflect on experiences through two intercultural collaborations: (1) Global Visions Through Mobilizing Networks: Co-Developing Intercultural Music Teacher Education in Finland, Israel and Nepal (a research sub-project in Nepal), and (2) A collaboration between Malmö Academy of Music and Vietnam National Academy of Music under a project Supporting Vietnamese Culture for Sustainable Development. We reflect on these processes through core concepts of affective actions and micropolitics. Our aim is to contribute to knowledge building in the field of sustainable institutional change aiming for globally appropriate music teacher education.
\end{abstract}

Keywords Institutional development - Micropolitics · Affective action · Teacher education · Music education

\footnotetext{
V. Timonen $(\bowtie)$

Sibelius Academy, University of the Arts Helsinki, Helsinki, Finland e-mail: vilma.timonen@uniarts.fi
}

A. Houmann · E. Sæther

Malmö Academy of Music, Lund University, Malmö, Sweden

e-mail: anna.houmann@mhm.lu.se; eva.saether@mhm.lu.se 


\section{Introduction}

Ultimately, we need to reinvent ourselves (McLaren 1998, 260-261)

The cry to reinvent educators working in multicultural contexts includes academic, institutional, and individual dimensions. Individuals involved in an institutional change often find themselves in the middle of processes that can be emotionally challenging. To successfully conduct their educational work with intercultural qualities, they need to practice epistemological creativity and be ready to work in rapidly changing and unpredictable situations (Hebert and Sæther 2013). This chapter is based on our assumption according to which the painful, yet rewarding and necessary process of reinvention is one of the core characteristics of intercultural and collaborative work. Whilst focusing on teacher-researchers ${ }^{1}$ transformative processes, we contextualise their work within the frame of institutional change and intercultural teacher education as it unfolds in two contexts, namely the Academy of Finland funded research project Global Visions Through Mobilizing Networks: Co-Developing Intercultural Music Teacher Education in Finland, Israel and Nepal, ${ }^{2}$ and the 8-year-long collaboration between the Malmö Academy of Music (MAM) and the Vietnam National Academy of Music (VNAM) in Hanoi.

\section{Political and Educational Background}

The research is prompted by initiatives that actively aim to change and develop music teacher education to better respond to the demands of current issues, such as immigration, democracy, human rights and freedom of cultural expression(s). Such initiatives, to name a few, include: a teacher education project in Lebanon (Brøske and Storsve 2013); collaborative international master's degree programs, such as the Nordic Master of Global Music (GLOMAS) (Hebert and Sæther 2013); the cultural exchange projects aiming to facilitate student-teachers with intercultural experiences in a 'foreign' culture (Sæther 2003; Westerlund et al. 2015; Kallio and Westerlund in this volume); teacher exchange and curriculum development work (Houmann 2018); research on sustainability in traditional cultures (Schippers and Grant 2016); intercultural music camps, such as Ethno (Ethno 2016); and, finally, global efforts of developing intercultural music teacher education exemplified by the Global Visions research project. All three authors of this chapter are music educators and researchers who have invested multiple years totally immersed in intercultural music education projects in Gambia, Vietnam, Nepal and 'at home' in Finland and Sweden (Houmann 2018; Sæther 2003). This chapter therefore rests on

\footnotetext{
${ }^{1}$ We use the term teacher-researcher to indicate the teachers in the selected cases as 'practitioner -researcher' (Cain 2008).

${ }^{2}$ Later referred as the Global Visions project.
} 
the lived experiences of working with institutional change in global and multicultural contexts. We are not aiming at a comparison between projects carried out in Nepal and Vietnam, rather the focus is on teacher-researcher transformative processes, as experienced in different settings, sharing similar challenges.

We extend McLaren's (1998) concept of the reinvented educator in music teacher-researchers, scrutinize micropolitics (see e.g. Hoyle 1982; Pillay 2004), explore challenges, and assess positive affective actions (Wetherell 2012) of collaborative activities in two intercultural development projects. We elaborate on these concepts in later sections of the text and strive to grasp the nature of affective actions in the process of educational development, as this dimension contributes to a wider understanding of intercultural educational endeavors. We also reflect how the micropolitical climate of the institutions affected individual work participation.

\section{Programme Development in Two Intercultural Cases}

Program development in intercultural contexts offers opportunities to explore the nature of the demanding process of reinvention that concerns everyone involved. For the purposes of this chapter, we have selected two cases to examine collaborative transformation processes.

The first case is the Global Visions project's sub-study on collaboration of Finnish and Nepali teacher-researchers in the process of creating a new study program and curriculum for the Nepal Music Center (NMC) in Kathmandu in 20152016. The curriculum writing, planning, and programme launch were conducted and led by four teachers at NMC in collaboration with the first author of this chapter, Vilma Timonen. In 2015 a need for establishing more structured ways of conducting music education for advanced level students at NMC was recognized by the teachers and administrative staff. For the future needs of Nepal, demand for pedagogically trained musicians was prominent since music teacher education as such did not yet exist in the country. Building a new programme and its curriculum fit well with the aims of the institutional collaboration between Sibelius Academy and NMC. The collaboration offered a way of learning together and co-constructing knowledge while aiming for a concrete goal. As a result, a new study programme was launched in January 2016 as the first nine students started their studies in the Performance Diploma Programme.

The second case is a sub-project of the Supporting Vietnamese Culture for Sustainable Development programme. We draw on the study (Houmann 2018) on the development of the Music Education Department and music teacher education at the Vietnam National Academy of Music (VNAM) in Hanoi in 2008-2016. Anna Houmann, the researcher in the project and co-author of this chapter, was one of the project leaders within the program Supporting Vietnamese Culture for Sustainable Development. The main activities of this project were teacher and student exchanges, training courses in different music subjects both in Vietnam and in Sweden, and cultural exchanges between the two countries. The overall objective, creating condi- 
tions for openness and development towards democracy and respect for human rights, was at the core of this project through the implementation of music education. From the point of view that lack of access to cultural forms of expression is a form of poverty, music education could contribute to poverty reduction by strengthening the capacity of those who study music. Poverty reduction in this sense activates what Appadurai (2004) describes as a "capacity to aspire" - a resource for renegotiating positions in society - that could contribute to democracy and the right to cultural diversity by supporting education with different kinds of music. In this project, such processes were in action and the teachers hoped that, in the long-term, the results would reach a large amount of school children through music teacher education, and art in school activities.

Both cases have special characteristics and focus areas. In Vietnam, the overall objective of creating conditions for openness and development towards democracy and respect for human rights was at the core of the subproject. The project had two objectives, namely "to enhance mutual understanding between the two peoples through cultural exchange programs," and "to enhance knowledge and management capacity for people working in the field of culture in Vietnam and Sweden" (Houmann 2018). In Nepal, the focus was on capacity building through enhancing mutual learning by taking account participants' various backgrounds, and bringing local practices into discussion with the global-music education community.

Data examples from Kathmandu, Nepal were generated through reflective group discussions, diaries and written works, where the researcher and the four teachers reflected on their collaborative processes. This data is mirrored with lessons learned from the development activities of intercultural music education in Hanoi, Vietnam. In both contexts, the co-writing of educational documents and establishment of new study programmes required all participants, including the researchers, to expand their horizons from familiar to unfamiliar, to go through a transformational process within themselves, and to re-evaluate cultural and institutional conventions - that is, to go through a process of reinvention.

In the following, we use the data from Kathmandu and experiences from Hanoi to demonstrate: (1) the micropolitical climate of institutions, and (2) the key moments of affective actions in an individual's experiences that shaped the outcome of the intercultural music education work aiming for institutional development in Nepal and Vietnam. We examine the collaborative project work and the ways the role expectations changed along the way. Taking into consideration the flow of activities in the two projects, we discuss the affective actions and micropolitical climate that guide change in intercultural, collaborative educational efforts (such as this Global Visions sub-project and the collaboration between Malmö Academy of Music and Vietnam National Academy of Music). The mutual re-inventions prompted by these collaborative actions in Nepal and Vietnam are used to inform our discussion of intercultural music education. Finally, we discuss the potentials of affective actions for the future of music teacher education. 


\section{Moments of Affective Action}

Following Wetherell (2012), we use the concept of affective action as a pragmatic way to think about affect and emotion and as a way forward for social research, and as it expands on basic terms for emotions (sadness, anger, fear, surprise, disgust and happiness). Further, the concept opens the study of affective performances, affective scenes, and affective events: "Affective practice focuses on the emotional as it appears in social life and tries to follow what participants do. It finds shifting, flexible and often over-determined figurations rather than simple lines of causation, character types and neat emotion categories" (Wetherell 2012, 4). Hence, affective action cannot be reduced to any individual emotion. Rather, it refers to events, moments and experiences that shape the outcome of activities, and, as in the cases presented in this chapter, the developmental aims.

The study of affect is linked to the study of pattern: "Patterns are sometimes imposed, sometimes a matter of actively 'seeing a way through' to what comes next, and sometimes, like a repertoire, simply what is to hand"(Wetherell 2012, 16). Wetherell also argues that affect is about sense as well as sensibility, and that it is practical, communicative, and organised. She states that "affect does display strong pushes for pattern as well as signalling trouble and disturbance in existing patterns" (Wetherell 2012, 13). For instance, in Nepal, the NMC teachers were not used to being given the authorization to take educational leadership by constructing educational policy documents and practices. Thus, this process changed the usual patterns as described by one of the teachers:

\footnotetext{
I used to plan my lessons in my head and only later I would write it down in order to submit it to the authorised person, and/or an authorised person would give me the curriculum to be followed. But in this new NMC Performance Diploma this curriculum writing process has been totally different. The curriculum was written by us, a group of teachers who would teach in the program. We planned and wrote down the whole process. Instead of writing a "lesson plan" kind of syllabus, we decided to leave as much room as possible for the teacher to decide on the ways to reach the learning outcomes stated in the curriculum. (Reflective essay, August 2016, Teacher 2)
}

Affective practices have their own hierarchies, which define how practices, such as classroom activities and writing of educational documents (as in the cases at hand), are grouped and who gets to do what and when. These hierarchies lead to troubling questions regarding what relations an affective practice disrupts or reinforces. Power is crucial to the agenda of affect studies, and consequently Wetherell asks if emotional "capital" $(2012,17)$ makes sense, as an element of cultural or social capital.

According to Wetherell, affective practices vary in scale. They flourish in the individual, but can be played out on a larger scale, like shared jokes, collective moods and expressions of nationalism (Wetherell 2012). Thus, examination of institutional change from the viewpoint of micropolitical action, that can be described as an interaction shaped by group hierarchies and ideologies (Pillay 2004), is likewise needed. Pillay (2004) also draws our attention to the importance of issues of leader- 
ship, organisational goals and objectives. Power is important, as is a sense of being powerless. The power to influence may be exerted in various ways in an institutional hierarchy, which has an impact on those who have less or no power. Therefore, issues of power in micropolitical studies include unanticipated arenas of power, as for example the presence of silence as an expression of micropolitics.

In Kathmandu, the emotional challenges of accepting a leading role in educational change became prominent when the four teachers and Vilma jointly reflected upon the process a couple of months after the implementation of the new programme. Vilma asked the teachers whether they considered themselves as active agents in the process of change, perhaps even activists, since in many ways the new programme differed from the prevailing educational culture. The question remained unanswered as silence took over the discussion. On the following day, the researcher found the team members unsettled, anxious, and upset.

For me the change and activist word was... its... for me it is something that others determine not the things that we do. But, I think that's ... the things that we are doing is for a change and we are changing things. But for me personally, I think those things are determined by others rather than we ourselves. (Team discussion, March 2016, Teacher 3)

\section{Another teacher continued:}

Actually, yesterday I was thinking about ... those challenges and responsibility in whole. And, actually I think taking [it a] little deeply I found that more complex thing that we were never (...) used to. Listening... being in a role of activist kind of thing. (...) in our context we have not been so used to that kind of role in our society. So, lots of things that we need to discuss among ourselves.... We are not here to make any change (...) [to] the social responsibility and [to] not get to use that voice. Yes, I was thinking about that and get really confused after this discussion. (Team discussion March 2016, Teacher 1)

The quotes themselves do not capture the emotional struggle that was present in the conversation. The word "confused" was used many times in the above conversation (Team discussion March 2016) as in many others, as an expression of unsettled emotions and inner conflict. The teachers were struggling to express their thoughts in words and in a language that is not their mother tongue. Despite this struggle, no one withdrew from the group, but all remained committed to continue the communication, trying to make meaning out of what they were experiencing. The variety of emotions present in this particular conversation could be considered as a manifestation of a high level of affect-based trust that had developed among Vilma and the NMC teachers. This incident also highlights the meaning of silence that took place after the initial question. As it turned out, behind the reaction of silence, there was a world of emotions with significant relevance to the entire process of educational change happening in the institution.

Similar moments of confusion and critical affect-based situations can be detected in the project taking place in Vietnam. For example, the aim of highlighting human rights turned out to be ethically complicated as the Vietnamese teachers feared for sanctions from their institutional and political leaders for talking aloud about these matters. To Anna, this came as an unpleasant surprise. In her Swedish musiceducation context, human rights belong to the taken-for-granted aims, as do the 
aims of promoting student rights and musical diversity. The Vietnamese teachers appeared to be quite reluctant to discuss human rights with her from this standpoint. In retrospect, this reluctance turned out to be a result of the local history framing the international collaboration. Thus, in their efforts of implementing a new music teacher education in Vietnam, the participating teachers and researchers experienced a paradoxical situation in which national guidelines (e.g. MOET 2001, 2003, 2015; HERA 2005) pointed towards democratization, placing the teachers in a situation where they were supposed to implement change that no one wanted or dared to discuss.

As exemplified in both cases, in intercultural settings the nature of affective practice can be both an advantage and an obstacle towards creative development. As Wetherell (2012) points out, affective practices can be sometimes moveable, sometimes stubbornly fixed, and sometimes existing beyond talk, words, or texts.

\section{Intercultural Twists}

Since different cultures have their own 'lexicons' for somatic and affective experiences, it is almost inevitable to feel confused from time to time when working in a foreign culture. As stated by Wetherell, "there are no universal emotion concepts" $(2012,41)$. Therefore in their intercultural collaboration, participants coming from Finland and Sweden encountered distinct challenges. The obvious ones had to do with the researchers' geographical, educational and societal privilege position. The ongoing re-negotiation of goals and the means for achieving them forced the participants to stay flexible, open, and willing to accept the role of a learner in various ways. Stepping into a new context was anything but easy for the researchers. Vilma's field notes in Nepal reveal both frustration and inspiration:

I don't have any of my familiar surroundings. I am in a vacuum far from my own life, and have to learn everything from the beginning. I have to challenge all my earlier thoughts, there is no other option. In this intercultural work we are all learning from each other. I just have to keep on challenging my own thinking and keep on learning. (Researcher's diary, March 2016)

During the many years of encountering and collaborating with teachers, students and researchers in Vietnam, the constant need to reflect on provoking, surprising and inspiring moments prompted Anna to unlearn her previous conceptions. For her, the issue of 'copying and pasting' Western educational philosophies and structures became a major issue to deal with:

On a cautionary note, there is a risk [in] setting up a music teacher education [program] that adopts, somewhat uncritically, models of western education, including western models of music education. This could lead to archetypes of music education more closely aligned with European fine arts and music and less connected with the rich cultural tradition in Vietnam. The formalisation of the education process could undermine local artistic heritage and devalue the inclusion of more local community practices in music. (Houmann 2018) 


\section{Micropolitics and Trust}

The literature on affective actions and micropolitics helps us to examine interpersonal relations and the emotional climate in institutional development work from the point of view of trust and the multiple manifestations and forms play out. Trust is developed at the micropolitical level of educational change (Hoyle 1982). Moreover, trusting and trusted individuals are crucial for organisational ends to be met. In his research McAllister (1995) shows that affective trust, in addition to cognitive-based trust, plays an important role in institutional development. He shows the importance of understanding the affective qualities of work-related relationships. Interestingly, he refers to studies that show how affective trust is difficult to build in cross-cultural and multi-ethnic situations. Trust, and more specifically affective trust, is crucial for the outcome of organisational endeavours. However a path leading towards formation of trust, might be challenging in terms of data collection as it might include silences and sensitive data. Thus, in research this is often a neglected area, maybe because of this sensitive character (Hoyle 1982). However, as Bennet (1999) shows, change does happen when there is a trustful micropolitical climate. Thus, it is possible to understand micropolitics both positively and negatively. In educational developmental work, such as in the cases presented in this chapter, the interplay between the culture of an institution and the micropolitical activities within institutions utterly become a matter of an individual teacherresearcher and his/her capacity to find tools for leading the development process.

The importance of trust was recognized by the participants in both projects for whom the work often felt as emotionally intense. In the process in Nepal, the efforts of overcoming emotional challenges related to change were supported by the strong and positive relations between the team members - relations that grew stronger with time.

Working in a team and supporting each other has led us to build a strong foundation towards making a community which is motivated in growing music education in our society. (Reflective essay, August 2016, Teacher 1)

The emergence of mutual trust and the practice of sharing and learning from each other contributed to the building of necessary confidence for proceeding with the plans and activities.

Working in a team with the teachers has been fun and [I have been] getting to learn a lot from everyone. Sharing and communicating has made me learn in many different ways. [Learning] ways to approach while teaching with others' shared ideas has been a lot of help. Achieving the set goal with the collaboration and with the team has been rewarding and is building a sense of collective achievement and progress. Writing, reading and sharing the knowledge has made me learn a lot while doing it with the team and learning to teach in a team has been much easier. (Reflective essay, August 2016, Teacher 3)

In both contexts, the positive personal relationships became essential, requiring, however, enough time spent together, in formal and informal settings. As suggested by Hoyle, one is more likely to talk about the micropolitics of institutional life in settings outside the institution: 
When this aspect of organisational life is mooted, for example, on teachers' courses, there is a frisson of recognition and although course members have many tales to tell of micropolitical skulduggery, they prefer to tell them in the bar rather than submit them to analysis in the serious context of a course discussion. $(1986,125)$

This aspect of the development of trust can be clearly seen in the project in Nepal, where the sense of collegiality was decisively heightened in August 2015, when Vilma and the NMC teachers started to play music together. They organised and performed in a fundraising concert for victims of the earthquakes that had shaken Nepal the previous spring. Practicing and making music together also meant spending more time together, increasingly often outside of the official institution meetings. This provided an invaluable opportunity for deeper discussions that contributed to increased mutual understanding about each other's cultures and backgrounds.

In Vietnam, the use of peer coaching and action research provided job-embedded and ongoing professional support and allowed music teachers to work together professionally, thereby eliminating isolation and developing deep and trusting relationships. It encouraged reflection and analysis of music teaching practice regarding teaching through, in and about traditional musics (Houmann 2018). Moreover, these methods created and built on the sense of trust between the Swedish and Vietnamese participants. A joint presentation of the endeavours at the 2010 ISME conference in Beijing turned out to be a key moment in further enhancing that trust. The design of the project included teacher and student exchange that made it possible for the Vietnamese teachers to spend time at the Swedish institution for lengthy periods. Throughout the project the importance of informal gatherings and meetings, such as dinners, concerts, seminars, excursions and parties, became more and more prominent. In fact, it was during these informal moments when various important discussions took place and many confusions, which had occurred during formal meetings, were solved.

\section{Breaking the Familiar}

Changing patterns of action against the prevailing educational system was one of the key elements in both cases. The construction of the school curriculum in Vietnam concentrated on child-oriented activities, children's experiences, the importance of play, the process of activities, and individual differences; further it sought to create of a learning environment for children, incorporate theory and practice, and link education with production. Many of these themes were new and perceived as challenges to achieve due to the long tradition of Vietnamese culture having always been adult-oriented (Pham Thi Hong 2010). Whereas the old system focused on the outcome, the new curriculum emphasized the process. Due to the reluctance of institutions to keep up with the change to accommodate the 'reinvented' teacher, curriculum renovation is still ongoing (Houmann 2018).

Questions concerning a student-led approach to teaching was a topic of many discussions in Nepal as well. The hierarchical relationship between teachers and 
students raised memories as the teachers looked back on their own experiences in school, where a fear of teachers and other authorities had been pervasive. As students, they had had little possibility for making decisions in the classrooms. In their own work as teachers, their aim had been to reduce the power gap between teachers and students and in this way to create a more equal learning environment where students' voices would be present in teaching and learning.

Another very good thing that has grown in me is that I now have confidence in sharing a lot with them [the students]. Earlier I would hesitate to tell the students that I don't know the answer [to] a question, now I do not hesitate to ask them for help and to find the answer together. I think this will help me being a teacher, and also to promote teaching as a learning process. (Reflective essay, August 2016, Teacher 2)

Navigating between an authoritarian, hierarchical way of teaching, where the teacher is seen as the 'person who knows all,' and a more equal, non-hierarchical relationship, where the teacher could be seen as a co-learner, has not been simple and straight-forward for the Nepali teachers. It required plenty of self-reflection and also openness for the teachers to reflect on their own educational past, including even the painful incidents one would rather not talk about. It is clear, however, that at its best the self-reflection led the teachers to a deep sense of accomplishment and motivation and helped them to stay true to their inner values, emphasizing and working towards equality in their classrooms.

The three-year performance program [that] was developed in the process where I as a teacher started to provide an environment for both the student and myself to learn together. (Reflective essay, August 2016, Teacher 3)

During the process, the four NMC teachers and the teacher-researchers from Finland formed a study group in which they discussed the literature related to various music education practices around the world in relation to their respective contexts. This provided opportunities to relate their current teaching practices to the wider musiceducation-research and global-teaching communities, which in turn, gave means for self-reflection.

Moving forward to another step is being self-aware and creating awareness in a team that has helped us in understanding a broader meaning of music education. This is how I begin exploring different dimensions of my teaching and classroom activities. (Reflective essay, August 2015, Teacher 1)

The reflexivity formed through the increased knowledge and understanding of one's own practices thus acted as a catalyst for taking more responsibility and developing deeper agency in one's everyday work.

Being a teacher, having freedom to be myself and creative with teaching approaches has been new in the program and a way to motivate oneself. (Reflective essay, August 2016, Teacher 3)

In her researcher diary, Vilma reflects how the process opened up a new understanding of diversity for her. Being exposed to a different environment brought up new angles to teaching practices at her home institution and, through that, a heightened sensibility towards students' diverse backgrounds. 
Despite the many challenges along the way, participants in both projects identified many benefits from the intercultural collaborative actions. They placed much emphasis on the reinforcement of their role and the possibilities to use their professional skills as teachers.

Through this partnership [with the Sibelius Academy] we have definitely gained a lot. We are more confident about our work. This has built a sense of ownership and commitment among teachers which is important for any institution. (Reflective essay, August 2016, Teacher 4)

In Vietnam, music teachers had a sense of determination to overcome difficulties to adapt to the new requirements for the renovation of the school. Most of them grew dedicated to music education for the great cause and the benefit of the Vietnamese nation. One of the music teachers in the project stated that students at primary and secondary schools should be able to access music by sound, and art by color. "Let them feel music and art before forcing them to learn in the rigid way teachers are following the guidelines of the Ministry of Education and Training" (Houmann 2018).

\section{Discussion and Conclusion}

In this chapter, we have identified and discussed the various challenges that individuals participating in intercultural educational development might face. Taking an active role in educational development and regenerating the usual patterns of action at the institutions in Nepal and Vietnam was emotionally challenging and even painful for the teacher-researchers involved. The concept of affective action (Wetherell 2012) helped us highlight how the participants had to deal with a sense of power as well as being powerless during the process of interaction. Differences between cultures, tradition and values, the difficulties in understanding one another, as well as the recognition of privileged positionings caused unsettled emotions in everyone involved. Through facing many challenges along the way, affective actions such as building trust, collegiality beyond national borders, collaborative knowledgebuilding, increased agency, and a sense of ownership were identified as driving forces. As discovered in the Global Visions project sub-study in Nepal, the important expansion of teachers' horizons to encompass a wider professional community via intercultural interactions, including collaboration, and discussions about scholarly literature, can indeed act as a springboard to transformative professionalism. Indeed, the collaboration provided new contexts in which teacher-researchers were able to rework and rejuvenate practices as they established and developed them.

The experiences reflected in this chapter highlight the importance of various aspects of micropolitics, as outlined by Hoyle (1982). Overcoming the challenges was possible through strong collegiality and support for each other formed within the team in Nepal. This required plenty of time outside the institution in informal settings talking, eating, and making music together. Also, silence played an impor- 
tant role and required a great deal of contextual sensitivity and understanding. Undoubtedly there are challenges in describing, let alone interpreting, what is not being said. However, the relevance of silence was clearly manifested throughout the work. In order to understand the events, the most important question often was: What were the questions that remained unanswered?

This chapter argues for the need to consider emotional and cognitive aspects of change in order for the development efforts to succeed. The importance of developing emotional capital of stakeholders through affective actions can enable educational change. Thus, far from static retrospection, what we have demonstrated here is an analysis which aims to provide ways of re-conceptualizing notions of teacher professionalism in music teacher education. It does so by highlighting the tensions that are shaping the discourses and practices of teacher professionalism. We also envision the importance of music education research as a means for reinventing the professional development of music teachers, and as a strategy for developing the knowledge required for teaching music through affective actions. From our perspective, this contributes to establishing a new type of music teacher professional. We would encourage institutions to support strategies that would help rebuild public trust and interest in the music teaching profession and to mobilize music teachers so that they can be in control of the agenda for reclaiming the terrain of music teacher professionalism. Teacher inquiry and building strong supportive teacher-researcher communities, also across national borders as affective action, are initiatives whereby music teacher professionalism can be developed and reinvented.

Developing new forms of music teacher education stands therefore at the core of developing new forms of professionalism and professional identity among music teachers. The complexity of competing needs and the possibilities for conflict of interest and misunderstandings regarding what is seen to be in the best interest of music teachers and their students all have to be carefully negotiated. Indeed, cooperation between various stakeholders can be a veritable minefield. Developing new forms of music teacher professionalism demands the development of new skills. In order to move beyond old forms of music teacher professionalism, the work of music teaching needs to be redefined and reinvented. This is not only in terms of the skills required in classrooms to ensure effective learning outcomes by students, but also in terms of the needs of music teachers as teacher-researchers.

Hence, systematic development of music teachers as an active part of change has the potential to create a music education culture that engages with diversity, trust and respect both within society as a whole and within its education system in particular. This development includes inspiration and innovation, issues of responsibility and sustainability, and brings together government policy, professional involvement, and public engagement. Successful globally aware music education requires highly confident music teachers who are willing to explore new ideas and approaches. Affective actions should not only be put into curricula but should be recognised as a tool for deep mutual and sustainable development. In other words, 
it requires making music education a creative and inspiring site of teaching and learning. A music teacher that acts locally but thinks globally, is changing the world with music education.

This publication has been undertaken as part of the Global Visions through Mobilizing Networks project funded by the Academy of Finland (project no. 286162).

\section{References}

Appadurai, A. (2004). The capacity to aspire: Culture and the terms of recognition. In V. Rao \& M. Walton (Eds.), Culture and public action (pp. 59-84). Stanford: Stanford University Press.

Bennet, J. (1999). Micropolitics in the Tasmanian context of school reform. School Leadership and Management, 19(2), 197-101.

Brøske, B. Å., \& Storsve, V. (Eds.). (2013). Løft blikket, gjør en forskjell. Erfaringer og ringvirkninger fra et musikkprosjekt $i$ Libanon. Oslo: Norges musikkhøgskole.

Cain, T. (2008). The characteristics of action research in music education. British Journal of Music Education, 25, 283-313.

Ethno. (2016). http://www.ethno-world.org/. Accessed 4 Nov 2016.

Hebert, D., \& Sæther, E. (2013). "Please, give me space": Findings and implications of the GLOMUS intercultural music camp, Ghana 2011. Music Education Research, 16(4), 418-435.

Higher Education Reform Agenda (HERA). (2005). Fundamental and comprehensive reform of higher education in Vietnam 2006-2020. Resolution no. 14/2005/NQ-CP, dated 2 November 2005.

Houmann, A. (2018). Traditional musics in music education - The sound of (r)evolution. In Traditional musics in the modern world: Identity, transmission, evolution and challenges, Leung, B-W (Ed.), Traditional musics in the modern world: Identity, transmission, evolution and challenges (pp. 113-128). New York: Springer.

Hoyle, E. (1982). Micropolitics of educational organisations. Educational Management and Administration, 10, 87-98.

Hoyle, E. (1986). The politics of school management. London: Hodder and Soughton.

McAllister, D. J. (1995). Affect- and cognition-based trust as foundations for interpersonal cooperation in organizations. Academy of Management Journal, 38(1), 24-59.

McLaren, P. (1998). Life in schools. An introduction to critical pedagogy in the foundations of education. New York: Longman.

Ministry of Education and Training MOET. (2001). The education development strategic plan for 2001-2010 (Decision no. 201/2001/QD-TTG, 28 December 2001). Hanoi: Ministry of Education and Training MOET.

Ministry of Education and Training MOET. (2003). Report on the status quo of devolution in Vietnam's educational management and recommendations (Project in Assistance to the MOET No ala/8-o124). Hanoi: Ministry of Education and Training MOET.

Ministry of Education and Training MOET. (2015). Viet Nam: Education for all 2015 national review. [Online]. http://unesdoc.unesco.org/images/0023/002327/232770e.pdf. Accessed 1 May 2018.

Pham Thi Hong, T. (2010). Implementing a student-centered learning approach at Vietnamese Higher Education Institutions. Journal of Future Studies, 15(1), 21-38.

Pillay, V. (2004). Towards a broader understanding of the micropolitics of educational change. Perspectives in Education, 22(1), 129-138. 
Sæther, E. (2003). The Oral University. Attitudes to music teaching and learning in the Gambia. Malmö: Malmö Academy of Music, Lund University.

Schippers, H., \& Grant, C. (Eds.). (2016). Sustainable futures for music cultures. An ecological perspective. New York: Oxford University Press.

Westerlund, H., Partti, H., \& Karlsen, S. (2015). Teaching as improvisational experience: Student music teachers' reflections on learning during a bi-cultural exchange project. Research Studies in Music Education, 37, 55-75. https://doi.org/10.1177/1321103X15590698.

Wetherell, M. (2012). Affect and emotion: A new social science understanding. London: Sage.

Open Access This chapter is licensed under the terms of the Creative Commons Attribution 4.0 International License (http://creativecommons.org/licenses/by/4.0/), which permits use, sharing, adaptation, distribution and reproduction in any medium or format, as long as you give appropriate credit to the original author(s) and the source, provide a link to the Creative Commons licence and indicate if changes were made.

The images or other third party material in this chapter are included in the chapter's Creative Commons licence, unless indicated otherwise in a credit line to the material. If material is not included in the chapter's Creative Commons licence and your intended use is not permitted by statutory regulation or exceeds the permitted use, you will need to obtain permission directly from the copyright holder.

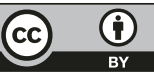

